Western University Scholarship@Western

1973

\title{
The Effectiveness of Intra-Island Industrial Incentives in Puerto Rico
}

Robert S. Woodward

Follow this and additional works at: https://ir.lib.uwo.ca/economicsresrpt

Part of the Economics Commons

Citation of this paper:

Woodward, Robert S.. "The Effectiveness of Intra-Island Industrial Incentives in Puerto Rico." Department of Economics Research Reports, 7319. London, ON: Department of Economics, University of Western Ontario (1973). 
Research Report 7319

THE EFFECTIVENESS OF INTRA-ISLAND INDUSTRIAL INCENTIVES IN PUERTO RICO*

by

Robert S. Woodward ${ }^{* *}$

October, 1973 


\section{Introduction}

The effectiveness of regional industrial incentives should be an important determinant of a government's choice among policies which attempt to reduce regional employment disparities. Within the 1 imited objective of equalizing employment opportunities, any regional subsidy for manufacturers is an efficient policy instrument only if its impact on local jobs is found to be at least as great per dollar as the impact of alternative public expenditures. As one step towards measuring relative employment impacts of alternative public expenditures, this paper examines the increased employment caused by a particular set of regional industrial subsidies--Puerto Rican intra-island incentives.

Examination of intra-island location decisions of Puerto Rican export manufacturers provides a unique opportunity to determine the effectiveness of regional industrial incentives for several reasons. First, since substantial variations exist in the mapping of the three individual incentives--plant construction, extra tax exemptions and cash grants--identification of the employment impact of each incentive is possible. Second, since export demand has been highly elastic at equal prices for all island locations, regional differences in employment growth cannot be attributed to differences in demand. Third, since the labor supply has been perfectly elastic at the same minimm wage for all locations, and since the supplies of capital and intermediate inputs have been perfectly elastic at the same prices for all locations, regional differences in employment growth cannot be attributed to favorable labor, capital, or intermediate input supplies. 1

This paper's explanation of intra-island manufacturing employment differences is similar to the depressed-region model of Borts and stein. ${ }^{2}$ Where export demand and capital supplies are assumed to be perfectly elastic, they 
conclude that subsidies to the inelastically supplied resource--1abour--are optima1. As in the Borts-Stein model, export demands and capital supplies are highly elastic in Puerto Rico. However, Puerto Rican labor supplies are also elastic while the supplies of two additional inputs, entrepreneurship and 1and, are considered to be inelastic. Thus, this paper's conclusion--subsidies which increase the inelastically supplied inputs land and entrepreneurship are most effective-is parallel to that of Borts and Stein.

The effectiveness of the Puerto Rican incentives is examined according to the following outline. Section II includes the derivation of a labor demand equation and arguments supporting the aforementioned product demand and input supply elasticities. Brief discussions of the data and specification of the regression equations to be estimated are the subject of section III. The regression results are examined in Section IV. Direct cost calculations lead to the conclusion that government construction of standard industrial plants may be a more effective incentive per dollar than extra years of corporate tax exemption.

II. Mode1

Discussion of the model is undertaken in several sections. First, the product demand and several input supply elasticities are documented. Second, the labor demand function is derived which accounts for these elasticities. Third, an adjustment process which leads to a useful lag structure is assumed.

A. Product Demand and Factor Supplies

The perfect elasticities of export product demand and of the labor, capital and intermediate input supplies are important since they imply that no intra-island differences in these endogenously determined prices occur. The arguments supporting each of these elasticities are summarized briefly.

1. Product Demand.. The large percentage of production exported to the United States and the small volume of these exports in the United States market are sufficient to establish that the demand curves faced by Puerto Rican exporting firms are highly elastic at a price which equals the United States market price minus transportation costs. First, the United States is the largest 
market for Puerto Rican production, having purchased slightly over half of the island's domestic and export manufacturing shipments during the last two decades. of the eighteen industries reporting, eight industries in 1963 and seven industries in 1967 exported over seventy percent of their total shipments; in each year, ten SIC's exported fifty percent or more. ${ }^{3}$ These exporting industries, except for chemicals and petroleum whose new locations have all been within one complex, serve as the subject of this study. Regrettably, the lack of observations on each industry has made individual industry regressions impossible. Thus, only results for an aggregate of all export industries are reported.

Second, since Puerto Rican exports to the United States represent only a small fraction of the receiving United states markets, the island manufacturers are 1ikely to be price takers. For example, in 1967 no three-digit SIC Puerto Rican industry shipments to the United States represented as much as ten percent of the middle and south Atlantic states shipments in the same industry and year. 4 Export industries, therefore, face a highly elastic demand curve at a price determined by the United States market price minus shipping costs to the island and trucking costs from the plants to the ports. This truck "pickup and delivery" cost is the only difference in demand prices between island locations and will be included in the model.

2. Labor. Two theoretical arguments suggest that differential wages have had little importance in determining industrial location on the island. First, the island's small size and labor's mobility and willingness to commute mean that there have not been distinct labor markets with different wage levels. Second, as a result of the aggressive minimum wage legislation pursued in spite of Puerto Rico's uniformly high unemployment, average wages everywhere on the island have almost always approximated the industrial minimum wage. 
a. Mobility: On the basis of interviews with 1045 factory workers, Reynolds and Gregory ${ }^{5}$ found that workers were mobile as early as the midfifties in that they were willing both to move between municipalities and to work in a municipality other than their one of residence.

A Puerto Rico Planning Board study to define regions documents the large distances Puerto Ricans commuted in $1960 .^{6}$ A map from the study (see Figure 2) illustrates the amount of commuting into the three major metropolitan areas at that time. It demonstrates that many workers from some municipalities distant from San Juan commuted to the capital daily. And although not illustrated in this map, in recent years there has been considerable commuting from the three urban centers to plants located in more rural municipalities.

The importance of this worker mobility lies in the implied availability of a group of workers larger than the pool of unemployed in the plant's immediate vicinity. Regional wage differences resulting from a limited supply of potential employees are therefore not probable since most job seekers seem willing to travel considerable distances or to move their families in order to take advantage of job opportunities.

b. Minimum wage policies: The second argument for an elastic labor supply follows from the enactment of Puerto Rico's agressive minimum wage policies at a time when unemployment rates were high. ${ }^{7}$ Since 1940 when enforcement of the United States Fair Labor Standards Act $30 \notin$ minimum wage caused undue hardship and thus led Congress to enact a special provision for Puerto Rico, the island's industrial minimum wages have been determined on the basis of "the highest minimum wage rate... which 1) will not substantially curtail employment in such classification and 2) will not give a competitive advantage to any group in the industry". 8 

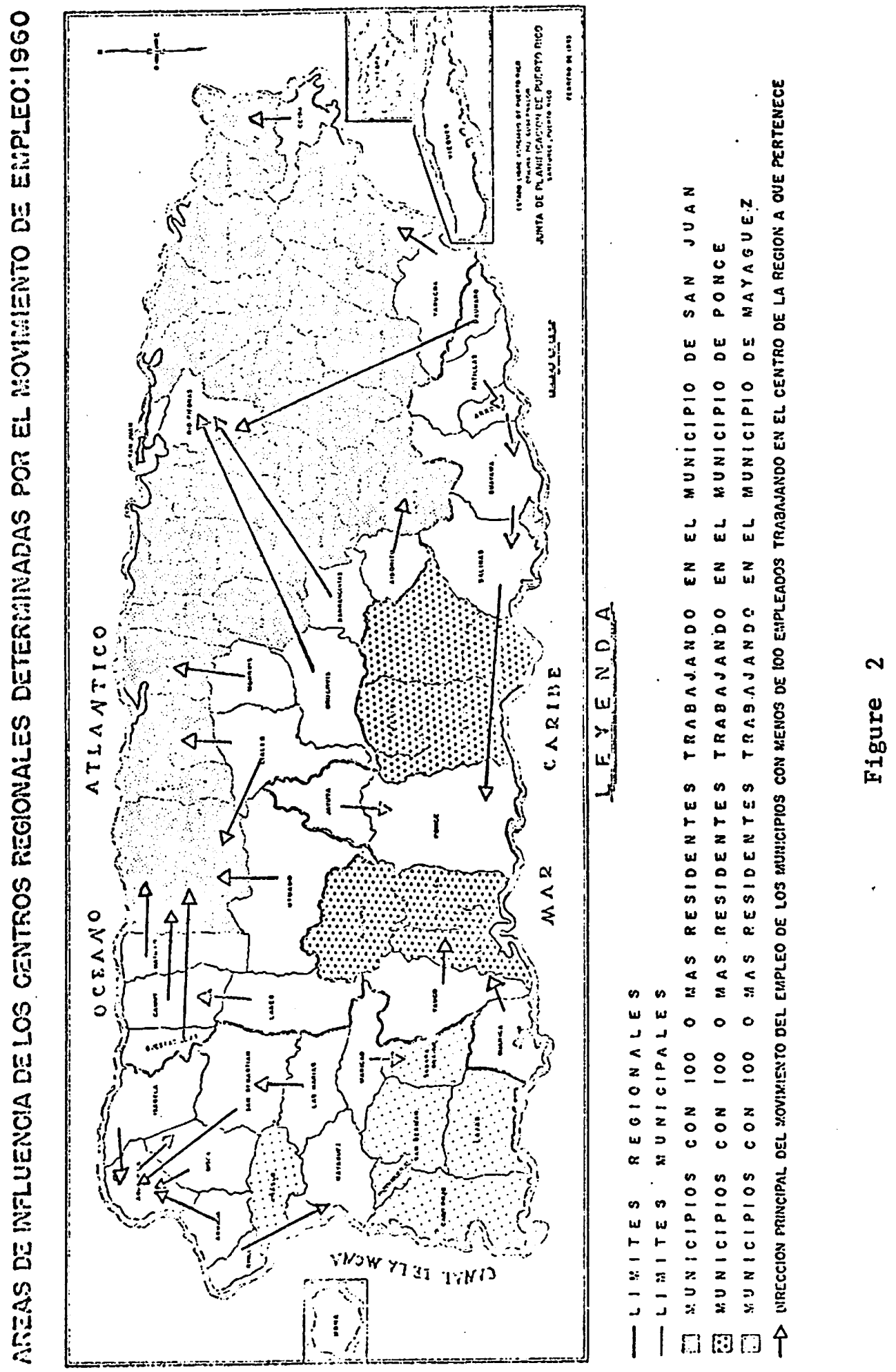
3. Capital and Intermediate Inputs. The arguments for negligible intraisland differences in the prices of both capital and transportable intermediate inputs parallel the argument that demand differences between regions were small. In short, most machinery, equipment and intermediate inputs are imported from the United States where Puerto Rican buyers represent a small proportion of the market. Regardless of the firm's source of funds, the plant location is unlikely to affect funds' availability or price. Therefore capital and intermediate input prices vary between locations only as a function of the intra-island truck "pickup and delivery" charge which will be included in the model.

4. Implications. Several implications follow from these product demand and input supply elasticities. First, the perfect elasticities imply that neither the quantity of product demanded nor the quantities of labor, capital or intermediate inputs supplied may be considered determinants of intra-island differences in employment growth. Additionally, endogenously determined differences in the prices of the product, labor, capital and intermediate inputs must also be excluded as determinants of intra-island differences in growth.

Nevertheless, exogenous differences in the cost of labor and capital attributable to one subsidy (Special Incentives), and in regional prices of the product and intermediate inputs caused by "pickup and delivery" trucking charges, may have been important. More specifically, the arguments in this section may be summarized in the following four equations.
1) $w=w_{e}+s_{L}$
2) $x=x_{e}+s_{K}$
3) $p=p_{e}+T_{Q}$
4) $\quad n=n_{e}+T_{N}$

where 
$w=$ the wage rate,

$x=$ the user cost of capital,

p = the product price,

$\mathbf{n}=$ the intermediate input price,

e = a subscript indicating exogenous determination,

$s_{L}$ and $s_{K}=$ the regional subsidy per employee and unit of capital, respectively, and

${ }^{T_{Q}}$ and $\tau_{N}=$ the per unit transportation cost of $Q$ and $N$, respectively.

Third, since no intra-island differences exist for $w_{e}, n_{e}, P_{e}$, or $n_{e}$

they cannot be included in the cross-section regression equation on municipal

observations. If they were included the $X^{\prime} X$ matrix would be singular.

Finally, since the product demand elasticity is perfect, the output

effect of a factor price change will be large. For factors such as land, entrepreneurship and public capital, which are important in Puerto Rico and which are not likely to be close substitutes for labor, the output effect is assumed to be larger than the substitution effect in the labor demand function. Thus, public capital construction and subsidies to land and entrepreneurship should increase the demand for 1abor.

\section{B. Labor Demand}

In this model, the derivation of a regional labor demand function depends most importantly upon the specification of the regional production function. For each export manufacturing industry, in each municipality, and at a particular point in time, output is assumed to be produced according to equation 5 . Implicit subscripts for industry, region and time are not included until they become important as the model is developed. 5) $Q=F(L, K, N, U, E$; $P K)$ where: 
$Q=$ manufacturing production in export industries;

$\mathrm{L}=$ quantity of labor;

$\mathrm{K}$ = quantity of machinery and equipment used in production;

$\mathrm{N}=$ intermediate inputs;

$\mathrm{U}=$ land inputs, being the amount of space and buildings used at particular locations;

$E=$ entrepreneurship input which may be interpreted either as managers, owners and/or highly skilled labor; and

$\mathrm{PK}=$ public capital inputs directly affecting manufacturing productivity, such as roads, communications services, and electrical, water and sewer capacities.

In a perfectly competitive model, the first-order condition may be considered as the demand for 1abor.

$$
\text { 6) } \quad w=p \cdot F_{L}
$$

where:

$$
\begin{aligned}
& w=\text { the wage rate; } \\
& \mathrm{p}=\text { the price of } Q ; \text { and }
\end{aligned}
$$

$F_{L}=$ the marginal physical product of the production function with respect to labor at given levels of labor, capital, intermediate inputs, land, entrepreneurship, and public capital.

Additionally, let

$x=$ interest and depreciation or the user cost of capital;

$\pi=$ profits or the returns to entrepreneurs;

$\mathbf{r}=$ rent or the yearly cost of land; and

$\mathrm{n}=$ the price of intermediate inputs.

The dependence of $F_{L}$ on the levels of other production inputs is expressed in equation 7 . 
7) $F_{L}=F_{L}(L, K, N, U, E ; P K)$

Substituting equation 7 into equation 6 and rewriting according to the implicit function theory,

8) $\quad L=f(w, P, K, N, U, E, P K)$

Because $\mathrm{N}$ and $\mathrm{K}$ have elastic supplies, it is convenient to solve the first order conditions and supply equations for the quantities $\mathrm{N}$ and $\mathrm{K}$ in terms of their prices. The solutions for $\mathrm{N}$ and for $\mathrm{K}$ are both substituted for $\mathrm{N}$ and $\mathrm{K}$ in equation 8 .

9) $\quad \mathrm{L}=\mathrm{g}(\mathrm{w}, \mathrm{p}, x, \mathrm{n}, \mathrm{U}, \mathrm{E}, \mathrm{PK})$

Differentiating with respect to time, letting - indicate $\frac{d}{d t}$ and momentarily ignoring the necessary adjustment mechanism,

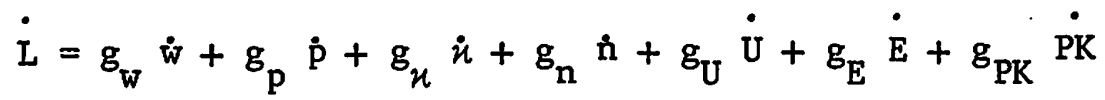

where $g_{X}=\frac{\partial g}{\partial X}$ for any $X$.

Substituting the first derivations of equations 1 through 4,

11) $\quad \dot{\mathrm{L}}=\mathrm{g}_{\mathrm{w}} \dot{\mathrm{S}}_{\mathrm{L}}+\mathrm{g}_{\mathrm{P}} \dot{\tau}_{\mathrm{Q}}+\mathrm{g}_{\mathrm{u}} \dot{\mathrm{S}}_{\mathrm{K}}+\mathrm{g}_{\mathrm{n}} \tau_{\mathrm{N}}+\mathrm{g}_{\mathrm{u}} \dot{\mathrm{U}}+\mathrm{g}_{\mathrm{E}} \dot{\mathrm{E}}+\mathrm{g}_{\mathrm{PK}} \dot{\mathrm{PK}}$

C. Lagged Ad justment Mechanism

Consideration of the lagged adjustment mechanism remains as the final step in the development of the model's conceptual foundations. An approach similar to a learning curve was chosen for its facility in measuring the size and the delay of increased employment caused by a limited number of exogenous shifts, such as new industrial incentives, in the labor demand schedule. Alternative lag structures, such as Koyck's, were rejected since much of the Puerto Rican data was available only in a first-difference form which does not easily fit the Koyck specification.

In particular, assume that the equilibrium level of employment, $L^{*}$, in any region and at the beginning of time period $t_{i}$ may be written 
12) $\quad L_{t_{i}}^{*}=\beta x_{t_{i}}+u_{t_{i}}$

where

$\beta$ is a vector of coefficients

$x_{t_{i}}$ is a vector of independent variables which determines $L_{t_{i}^{*}}^{*}$

$u_{t_{i}}$ is the error term in period $t_{i}$ and regional subscripts are implicit on $\mathrm{L}, \mathrm{X}$, and $\mathrm{u}$.

Between the beginning of any two time periods, $t_{i}$ and $t_{i+1}$, or during the period $t_{i}$, the optimum change in employment $d L_{t_{i}}^{*}$ equals

13)

$$
\begin{aligned}
d L_{t_{i}}^{*} & =L_{t_{i+1}^{*}}^{*}-L_{t_{i}}^{*}=\beta\left(x_{t_{i+1}}-\beta x_{t_{i}}\right)+u_{t_{i+1}}-u_{t_{i}} \\
& =\beta\left(d x_{t_{i}}\right)+u_{t_{i+1}}-u_{t_{i}} .
\end{aligned}
$$

However, if the time periods are short so that full adjustment is not achieved, the actual change in employment $d_{t_{t_{i}}}$ will be less than the optimum change.

In this research, $\mathrm{dL}_{\mathrm{t}_{i}}$ will be determined by a lag function $\mathrm{h}(\mathrm{t})$. Specifically, if $m$ is the number of time periods necessary for full adjustment of actual employment to optimal employment for one exogenous shock,

14)

$$
t_{i+m}
$$

$$
\int_{t_{i}} h(t) d t=1 \text {. }
$$

Thus for an incentive increase in a particular municipality in period $t_{0}$

15) $\mathrm{dL}_{t+i}=d L_{t+i}^{*} \int_{t+i}^{t+i+1} h(t) d t$

$$
=\left[\beta d x_{t+i}+u_{t+i}\right] \int_{t+i}^{t+i+1} h(t) d t, \quad i+1 \leq m .
$$


The importance of these arguments is that equation 11 can now be written

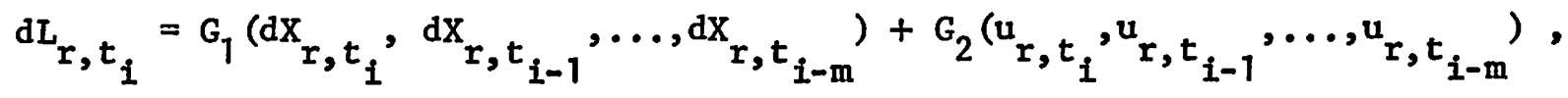

where the subscript $r$ refers to a particular region; the subscript $t_{i}$ denotes a particular time period; the function $G_{1}$ includes the influence of $\beta$ and $h(t)$; $\mathrm{dX}$ indicates the vector of independent variables in equation 11; and the function $G_{2}$ describes the influence of $h(t)$.

\section{Estimation}

The empirical estimation of the model indicated in equations 11 and 16 is reported in two sections. First, each regression variable is briefly explained and its data source discussed. The dependent variable is the change in export manufacturing employment in each of the 74 main island municipalities. Independent variables include three intra-island industrial incentives, one dumny for public capital construction, one pickup and delivery charge increase, and two variables which indicate the municipality's scale. Finally, the regression model is summarized.

\section{A. Variables}

1. Employment None of the available employment data sources which had the necessary spatial and industrial disaggregation was found to be highly suited for this study. Three sources were compiled and examined in detail: potential employment (POTEMP) from the promotional contracts of the Economic Development Administration (EDA), County Business Patterns (CBP) employment and average yearly employment from the financial statements of EDA promoted firms. The characteristics of each of these three sources are summarized in the following table.

Despite the high overall exaggeration, POTEMP was chosen over CBP employment because the industrial disaggregation of the promotions data allowed the separation of the export industries from the local industries whose size 
TABLE 1

Characteristics of Employment Data

$=$

Characteristics

of the Data

Industrial

Disaggregation

Time

Spatial

Disaggregation

Reliability

$\Xi$

Sample

Size

Multiplant

Employment

Attributed to the

Head Office?
4 digit SIC

POTEMP

CBP

Employment

only total

manufacturing

monthly data from

$7 / 60$ to $6 / 70$

municipalities

low: average exaggeration by almost 3 times, but spatial bias

considered unlikely

almost all new

locations or

expansions
EDA Promoted Firms' Financial Stat ements
March 31 levels

for 1959,62 ,

$64-69$

municipalities

high, but not perfect

all firms

no

yes
4 digit SIC

yearly averages

municipalities

high, but lower than CPB employment a significant number of firms and years missing because of investigations by the treasury Department

no<smiles>C1CCC1</smiles> 
is determined by the Iocal population. While adjustments will be made for the overall exaggeration, and although weak confirmation of incentive significance may be drawn from results of a slightly different specification using CBP employment, reliability of the conclusions about incentive cost effectiveness critically. depends upon the validity of the assumption that no spatial bias existed in the promotions exaggeration. Employment from EDA-promoted firm financial statements was rejected because of the number of missing observations and because employment for several firms, such as General Electric, with large numbers of plants throughout the island was reported by the head office only.

2. Industrial Plant Construction (dU) and Rents (dr). The supply of industrial land in each municipality has been affected by two distinct government actions, the construction of standard industrial plants and the changes in the rents for these plants. Thousands of square feet, dU, of Puerto Rico Industrial Development Corporation (PRIDC0) plant space built during a particular two-year period is considered to shift the supply of industrial land to the right. The one change in PRIDCO rents which occurred during the eight years examined by the study, a $\$ .20$ per foot increase in 1964, is considered to shift the land supply curve up in the municipalities where the increase occurred. Since only one increase occurred and since no data were available on comparable market rents or rent increases during the same period, the rent increase was included in the model as a dummy variable, $\mathrm{dr}$, equa1 to one for those municipalities whose rents were raised.

3. Tax exemptions $\left(\mathrm{d}^{03}, \mathrm{~d} \pi^{07}\right.$ and $\left.\mathrm{d} \pi^{37}\right)$. The second intra-island industrial incentive, extra years of corporate tax exemptions, is considered to increase the returns to entrepreneurs and thus the supply of entrepreneurs at every positive level of profits. Because the subsidy affects returns rather than the quantity directly, the subsidy is included in the model as $d \pi$. 
Total exemptions from corporate taxes--including income taxes, property taxes and 1icense fees--are possible because of the island's unique relation to the United States. ${ }^{9}$ To qualify for the basic ten-year holiday, a corporation must produce goods not manufactured on the island on or before January 2, 1947, produce one of the articles designated as important to the economy, or produce for export outside the United States. In practice, almost all locations or expansions qualify for at least the basic ten years. To qualify for more than ten years' exemption, a firm must have located in one of the designated municipalities.

Two changes--a 1961 increase from 10 to 13 years for some rural municipalities and a 1963 increase from 10 to 12,13 to 17 and 10 to 17 years for some municipalities--occured during the years studied. Because it was impossible to give cardinal values to any number of extra years of tax exemption, the 1961 and 1963 changes entered in the regression equations as dummy variables set to one for municipalities in which industries were eligible for increased exemptions. Three tax dummies-- $d \pi^{03}, \mathrm{~d}^{37}$, and $\mathrm{d} \pi^{07}$--were used. Municipalities whose exemption eligibility increased from 10 to 13 years in 1961 were indicated by the variable $d \pi^{03}$. Because most of these municipalities received an additional four years' exemption in 1963, it was impossible to separate the effect of the extra four years from that of the original extra three lagged one period. The dummy variable $d \pi^{37}$ was used for this extra three and four years exemption. In addition, a number of municipalities received the extra seven years exemption at one time in 1963. For this group the dummy variable $d \pi^{07}$ was set to one. The extra two years exemption given to some municipalities in 1963 was excluded from the regression because it was almost perfectly collinear with $\mathrm{d}^{37}, \mathrm{~d} \pi^{07}$, and $\mathrm{dr}$. Excluding these extra two years is justifiable on the a priori grounds that their expected impact is smaller than $\mathrm{d} \pi^{37}, \mathrm{~d} \pi^{07}$, or $\mathrm{dr}$. 
4. Special Incentives (dS+). The third intra-island subsidy, Special Incentives, is a cash grant to reduce some extra capital and labor costs which a firm may incur by locating in a rural municipality. While the amount of the grant depends upon the firm's investment and employment and the municipality in which it locates, it is impossible to attribute the grant directly to $\mathrm{K}$ or L. Thus, no differentiation is made between the capital and labor incentive and $\mathrm{dS}_{\mathrm{K}}$ is assumed to equal $\mathrm{dS}_{\mathrm{L}}$, 17) $\mathrm{ds}_{\mathrm{K}}=\mathrm{ds} \mathrm{L}_{\mathrm{L}}=\mathrm{ds}$

Changes which occurred during the $60^{\prime}$ s and on which information is available are limited to a few municipalities whose maximum eligibility either increased or decreased. Two dummy variables, dS+ and dS-, respectively, are used to indicate the municipalities with each of the two changes. As with rental and tax exemption changes, a dummy variable was necessary because of the difficulty in evaluating the relative magnitudes of the incentives' change.

5. Public Capital (dPK). Although public capital stocks are not industrial inputs in the normal sense some, but not a11, may be important determinants of municipal manufacturing activity. The important components include highway access to major metropolitan areas and electrical water and sewer capacities. Because of labor's mobility, school and hospitals are considered unimportant to industry. Changes in highway access, HW, is a dummy variable set to 1 whenever highway construction which increased the municipality's access to larger cities was ongoing.

Including the remaining public capital variables was not possible. Electric capacity is omitted since large electrical requirements could be satisfied at equal cost almost anywhere on the island. Although the water and sewer authorities now compile data on their systems capacities, they did not do so 
until 1968, the last year of the regression analysis. Distance from the three major metropolitan areas was also considered, but was rejected for lack of significance and inconsistency with the model

6. Pickup and Delivery Costs (dr). The 1962 increase in trailer truck pickup and delivery costs is indicated by the variable $\mathrm{d} \tau$. Importantly, this increase is the only change in product demand price. While the pickup and delivery zones did not follow municipal boundaries, each municipality was assumed to be in the zone of the municipality's major urban place. Although some small inaccuracies were likely, most plants did locate within the towns so that the occurrence of major errors seemed improbable. The dollar cost change, $\$ 5, \$ 10$, or $\$ 15$, of a trailer pickup or delivery between the plant site and the ports was selected since trailer containers have been the dominant mode of shipping. Moreover, since trailer rates do not depend upon the product shipped

$$
d \tau_{Q}=d \tau_{N}
$$

7. Population (POP) and Telephone Stations Per Capita (TSPC). In addition to the growth determinants thus far considered, certain agglomeration economies may also significantly determine employment changes. In short, larger metropolitan areas have tended to have services such as mechanics, industrial consultants, data processing facilities, accountants and 1awyers, which affect a firm's costs.

In the model described by equations 11 and 16, population is assumed to affect both the intercept term, $\beta_{0}$, and the magnitude or significance of the coefficients. To estimate the effect of agglomeration economies, population, POP, is entered as an independent variable. To test for the possibility that the incentives could be significant only because of the importance in a few large municipalities, regressions for each of the time periods were 
run on two sample populations, all municipalities and all municipalities with less than 40,000 people. This restriction eliminates about ten of the largest municipalities (see Table 2).

Telephone stations per capita, TSPC, is included as an additional proxy for the services available in larger metropolitan areas. While telephones might be considered a type of public capital, communication quality is better determined by the trunk and switching equipment rather than by the actual telephones. Regrettably, data on trunk and switching equipment were not easily divisible by municipal boundaries and could not be used.

\section{B. Regression Model Summary}

The full regression model is summarized in equation 19, where municipal subscripts are implicit for each variable. After some peeking at the data, two rather arbitrary decisions about the regression specifications were made. First, two-year time periods with one or two period lags were selected. In order to conservatively substantiate the lack of significance for some variables such as $\mathrm{HW}$, results for three periods $\left(\mathrm{HW}_{t}, \mathrm{HW}_{t-1}\right.$ and $\left.\mathrm{HW}_{t-2}\right)$ were included. Second, the results reported are for non-zero POTEMP observations. Thus the equations explain the importance of industrial incentives in determining the size of POTEMP in a municipality, given that it is greater than zero.

$$
\begin{aligned}
& d L_{t}=b_{0}+b_{1} d U_{t}+b_{2} d U_{t-1}+b_{3} d U_{t-2}+b_{4} d r_{t}+b_{5} d r_{t-1} \\
& +b_{6} d \pi_{t}^{03}+b_{7} d \pi_{t}^{37}+b_{8} d \pi_{t-1}^{37}+b_{9} d \pi_{t}^{07}+b_{10} d \pi_{t-1}^{07} \\
& +b_{11} d S+t_{t}+b_{12} d S++_{t-1}+b_{13} d S-{ }_{t}+b_{14} d S-{ }_{t-1}+b_{15} H_{t} \\
& +b_{16}{ }^{H W} W_{t-1}+b_{17} \mathrm{HW}_{t-2}+b_{18} d_{t}+b_{19} d_{t-1}+b_{20} d_{t-2} \\
& +b_{21} P_{t}+b_{22} T_{S P C}+g\left(u_{t}, u_{t-1}, u_{t-2}\right) \text {, }
\end{aligned}
$$


Table 2

Population of the Largest Municipalities

1960,1965 and 1970

(thousands)

\begin{tabular}{|c|c|c|c|c|c|}
\hline \multicolumn{2}{|c|}{1960} & \multicolumn{2}{|c|}{1965} & \multicolumn{2}{|c|}{$1970^{a}$} \\
\hline San Juan & 449.5 & San Juan & 491.6 & San Juan & 455.4 \\
\hline Ponce & 144.9 & Ponce & 152.2 & Ponce & 156.5 \\
\hline Mayaguez & 83.4 & Bayamon & 93.0 & Bayamon & 154.4 \\
\hline Bayamon & 71.9 & Mayaguez & 85.7 & Carolina & 108.0 \\
\hline Arecibo & 69.5 & Arecibo & 79.8 & Caguas & 95.0 \\
\hline Caguas & 64.8 & Caguas & 71.2 & Mayaguez & 86.3 \\
\hline Aguadilla & 47.6 & Aguadilla & 50.6 & Arecibo & 73.3 \\
\hline Carolina & 40.8 & Carolina & 49.7 & Guaynabo & 65.6 \\
\hline \multirow[t]{3}{*}{ Utuada } & 40.3 & Utuado & 45.3 & Aguadilla & 51.3 \\
\hline & & Guaynabo & 45.2 & Toa Baja & 46.9 \\
\hline & & Cayey & 41.4 & & \\
\hline
\end{tabular}

Note: All the remaining municipalities have populations less than 40,000 .

a Between 1965 and 1970 the rural municipalities of Utuado and Cayey fell below 40,000 due to emigration. 
where "t" indicates the initial time period

"dL" indicates change in employment in export manufacturing industries

"du" indicates thousands of square feet of PRIDCO construction

"dr" indicates a dummy variable having the value "1" for those municipalities whose PRIDCO rents increased and "O" otherwise

"d $\pi$ "3" indicates a dummy variable having the value " 1 " for those municipalities whose tax exemption increased from 10 to 13 years and "0" otherwise

"d $\pi^{37 " ~ i n d i c a t e s ~ a ~ d u m m y ~ v a r i a b l e ~ h a v i n g ~ t h e ~ v a l u e ~ " ~} 1$ " for those municipalities whose tax exemption increased from 13 to 17 years and "0" otherwise

"d $\mathrm{d}^{07}$ " indicates a dummy variable having the value " $"$ for those municipalities whose tax exemption increased from 10 to 17 years and "0" otherwise

"dSt" indicates a dummy variable having the value "1" for those municipalities whose Special Incentives increased and "0" otherwise "ds-" indicates a dummy variable having the value "f" for those municipalities whose Special Incentives decreased and "0" otherwise "HW" indiçates a dummy variable having the value " 7 " for those municipalities in which highway construction occurred and "0" otherwise

"d $\mathrm{T}$ " indicates the dollar increase in pickup and delivery charges of a trailer truck

"POP" indicates municipal population in thousands "TSPC" indicates telephone stations per capita. 

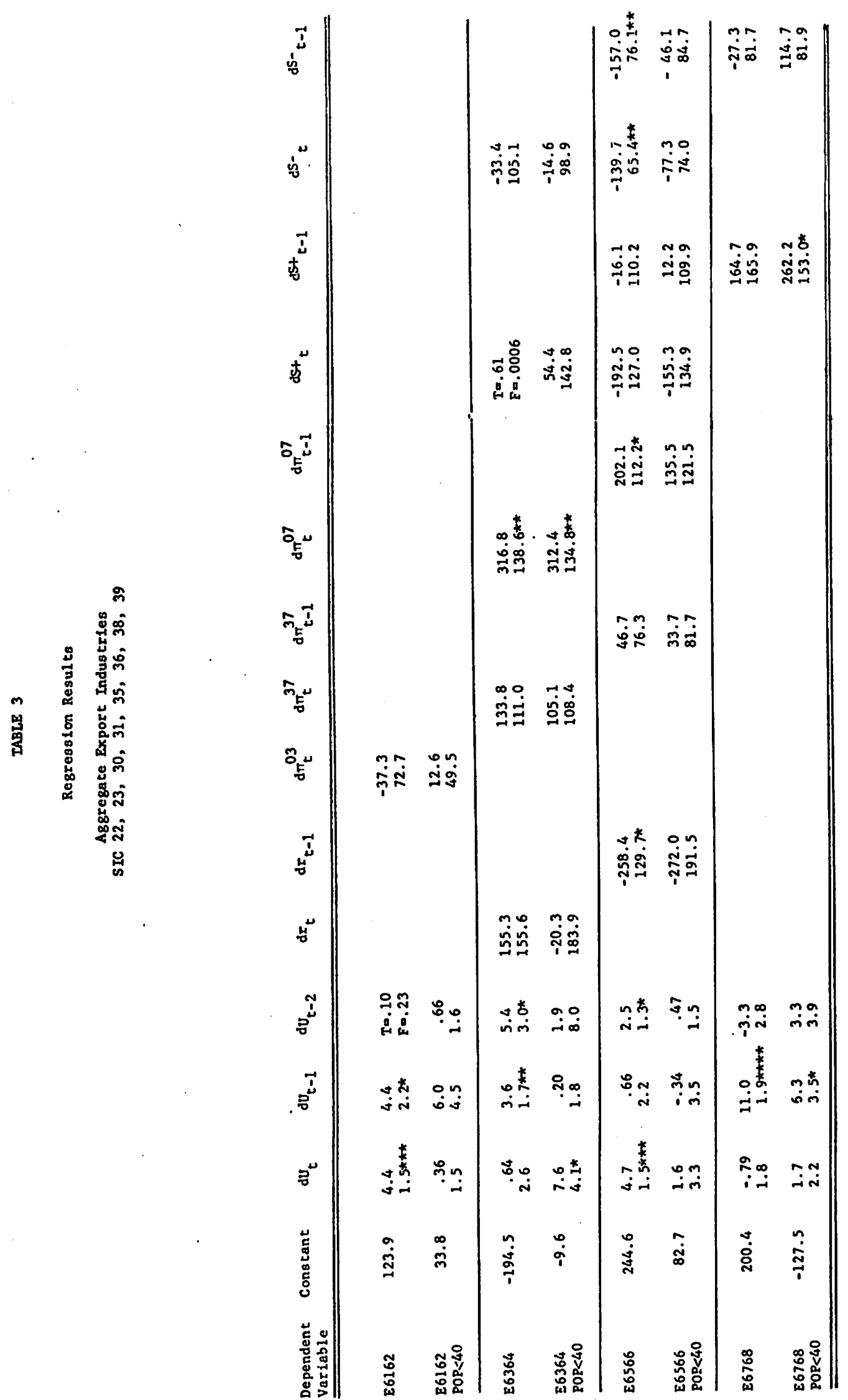


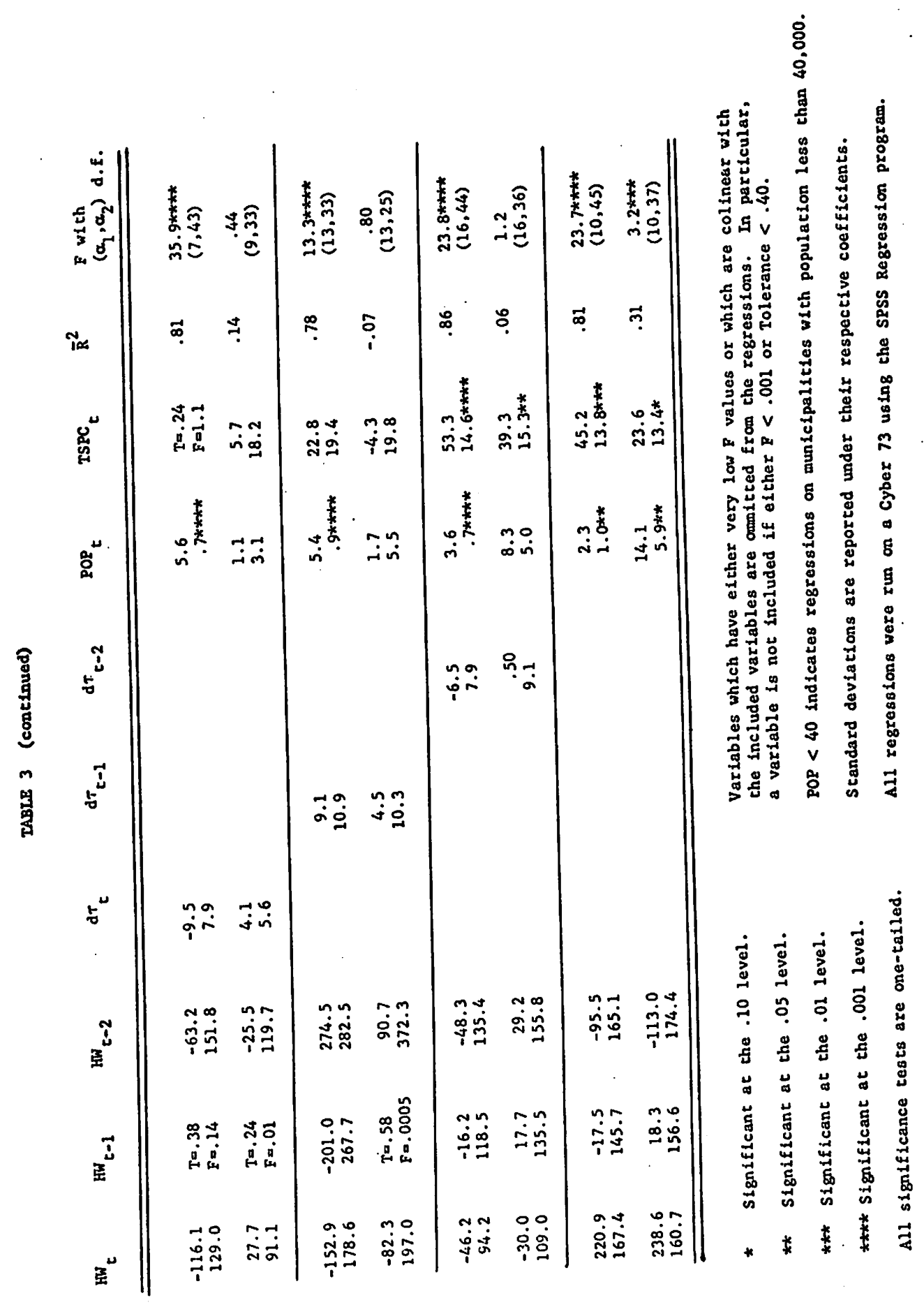


IV. Regression Results

The regression results are reported in two sections: a review of the significance of each coefficient and an analysis of the possible cost-effectiveness conclusions.

\section{A. Variable Significance}

The results for four two-year periods are reported in Table 3 . A discussion of the conclusions which may be drawn from the estimated coefficients proceeds from left of the table.

1. PRIDCO Construction (dU). Subject to two restrictive qualifications, PRIDCO construction was found to be highly significant in a number of the regressions. First, with two slightly significant exceptions, PRIDCO construction was not a significant $(P<.10)^{10}$ determinant of promoted employment in municipalities with less than 40,000 people. Thus, PRIDCO construction is seemingly not an effective determinant of employment growth in the smaller municipalities.

Second, considerable difference occurs between the significance of the construction in different two-year periods (see Table 4). For example, the 1961-62 construction was high1y significant that year $(b=4.4, P<.01)$, somewhat less significant in $1963-64(b=3.6, P<.05)$ and still significant in 1965-66 $(b=2.5, P<.10)$. The construction in 1965-66 gave similar results. In contrast, the PRIDCO construction during 1963-64 did not significantly correlate with promoted employment in any year except for a slight significance in the municipalities under 40,000 population during 1963-64 $(b=7.6$, $\mathrm{P}<.10$ ).

2. PRIDCO Rent Increase (dr). In the regression on all municipalities, increasing the rents correlates with a large, but marginally significant, decrease $(b=-258.4, P<.10)$ in promoted employment. While the size and 
TABLE 4

\begin{abstract}
New Jobs Per Thousand Square Feet
Summation of the Significant PRIDCO Construction

Coefficients
\end{abstract}

\begin{tabular}{|c|c|c|}
\hline $\begin{array}{l}\text { Period of } \\
\text { Construction }\end{array}$ & $\frac{A 11}{\text { Municipalities }}$ & $\begin{array}{c}\text { Municipalities } \\
\text { with Population } \\
\quad<40,000\end{array}$ \\
\hline $1959-60^{*}$ & 9.8 & 0 \\
\hline $1961-62$ & 10.5 & 0 \\
\hline $1963-64$ & 0 & 7.6 \\
\hline $1965-66^{*}$ & 15.7 & 6.3 \\
\hline
\end{tabular}


small significance of the coefficient is surprising given the small impact the rent increase is likely to have on most firms' profits, dr also indicates those municipalities which got no extra tax exemptions in 1963. Since not receiving tax exemptions also should reduce a municipality's relative employment growth, the significance and magnitude of RZIC may be explained by the combined tax and rent effects.

3. Extra Tax Exemption $\left(\mathrm{d}^{03}, \mathrm{~d}^{37}, \mathrm{~d} \pi^{07}\right)$. Although the coefficients are positive, granting three, $\mathrm{d} \pi^{03}$, and then four, $\mathrm{d} \pi^{37}$, extra years of tax exemptions did not significantly correlate with increased promoted employment. Nevertheless, granting seven extra years exemption, $\mathrm{d} \pi^{07}$, did significantly correlate with 518 and 312 jobs in the regressions on all municipalities and small municipalities, respectively. Interestingly, although the size of the municipality was an important determinant of the PRIDCO construction impact, the coefficients of $\mathrm{d}^{07}$ in the 1963-64 full and restricted regressions are almost identical $(b=316.8, P<.05$ and $b=312.4, P<.05)$.

4. Special Incentive Changes (dSt and dS-). On the whole, support for rejecting the hypothesis that the Special Incentive changes had no effect is scarce. Although the 1967-68 coefficient on the lagged increase in Special Incentives $\left(\mathrm{dS}_{\mathrm{t}-1}\right)$ is significant $(\mathrm{b}=262.2, \mathrm{P}<.10)$, the significance level is low and three of the eight coefficients are negative.

While the evidence on Special Incentive decreases is slightly better, strong conclusions are still not possible. Since only two of the eight coefficients are significant and most of the remaining six are negative, the best possible conclusion is that the Special Incentive changes have important impacts some of the time. 
5. Highway Construction (HW). The lack of significance of HW makes it impossible to reject the null hypothesis that highway construction had no impact on employment growth in exporting industries. Nevertheless, the large variances of $\mathrm{HW}^{\prime} \mathrm{s}$ coefficient in several of the regressions, especially in those on the limited sample, suggests that highway construction may have had an important impact in some, but not a11, municipalities.

6. Pickup and Delivery Charges $\left(d_{T}\right)$. Evident1y, the increased trucking rates had no measurable impact on export manufacturers' employment decisions. The null hypothesis that $\mathrm{d} T$ had no impact cannot be rejected.

7. Population (POP). The conclusions which may be drawn from the POP coefficients are indeed interesting. From 1961 to 1966, POP is high1y significant in the full sample regressions, but insignificant otherwise. These results are consistent with the hypothesis that agglomeration economies, and thus population, are important determinants of manufacturing location decisions only in the municipalities with populations greater than 40,000 .

In contrast, while in 1967-68 the POP coefficient is sma11 and significant at a lower level in the full regression $(b=2.3, P<.05)$, it is large and significant $(b=14.1, P<.05)$ in the 1 imited regression. This increased POP significance in the small, but not the large, municipalities is consistent with a change in export manufacturers' location patterns. It suggests that either industrial services are becoming available in the larger of the municipalities with less than 40,000 people or that firms are becoming less sensitive to the availability of these services. Whatever the reason, the regressions suggest an optimistic note that employment growth, even without additional industrial incentives, may be occurring in at least some of the municipalities with less than 40,000 people. 
8. Telephone Stations Per Capita (TSPC). The TSPC significance in both regressions from 1965-68 is taken as weak, but additional confirmation that industrial services have been important determinants of export manufacturing locations.

\section{B. Cost-Effectiveness}

Although firm conclusions about the relative cost-effectiveness of the significant industrial incentives are not possible because of both the lack of data and the unreliability of POTEMP, some preliminary comparisons may be drawn. In particular, this section uses available information to compare the government's after-tax expenditures per job attributable to PRIDCO construction and to extra years of tax exemption. An adjustment required to offset the three-fold exaggeration in total promotions is included after other job cost calculations.

1. Direct Costs. On the basis of the significant coefficients summarized in Table 4, between 6.3 and 15.7 jobs may be attributed to each thousand square feet of PRIDCO construction. Since construction costs ran between $\$ 6,800$ and $\$ 8,800$ per thousand square feet, ${ }^{11}$ each new job cost PRIDCo between $\$ 1,396$ and $\$ 433$. However, much of this initial expense is 1ikely to have been recovered by rental payments.

In order to reduce the construction costs by rental payments, the actual rents as a percent of construction costs are compared with hypothetical rents necessary to capitalize each dollar of construction according to the following formula:

$$
\begin{aligned}
& \text { cost per } \mathrm{job}=\left(\frac{\text { Construction cost per thousand square feet }}{\text { Number of } j \text { obs per thousand square feet }}\right) \times x \\
& {\left[1-\left(\frac{\text { Actual rent as a } \% \text { of construction costs }}{\text { Rent (as a \% of construction cost })}\right)\right] } \\
& \text { required to capitalize the building }
\end{aligned}
$$


Equation 20 implicitly assumes that construction costs are equal everywhere on the island and that the buildings are fully rented.

In metropolitan San Juan PRIDCO annual rents have been between $10.8 \%$ and $14.1 \%$ of construction costs. If a plant is rented for 16 years and if the appropriate discount rate is $6 \%$, the rent necessary to capitalize the building is $9.9 \%$. Substituting this information into equation 19 and assuming an average $90 \%$ occupancy rate, PRIDCO earned between $\$ 35$ and $\$ 533$ per job created by PRIDCO construction in the San Juan $Z$ one.

In the most rural zone, rents have been between $5.7 \%$ and $8.8 \%$ of construction costs. Assuming the same building life, discount rate and an average occupancy rate of $80 \%$, each employee attributable to PRIDCO construction cost the agency between $\$ 58$ and $\$ 711$.

The direct cost to the government of granting a municipality extra years of tax exemption is the present value of the new firms' yearly taxes which the government does not collect during the extra years of exemption. Such yearly taxes foregone by the government depend upon the size and profitability of the firm or firms attracted to the municipality. If each firm earns the average profit per employee in 1964, approximately $\$ 2,000$, then the 200 employees would generate $\$ 400,000$ yearly in corporate revenue. The tax on that revenue is determined by the number of firms that earn it. Based on the 1970 tax laws, if there are four establishments with fifty employees, the average employment per establishment, the yearly tax bill would be $\$ 115,000$. If all two hundred employees worked for the same establishment, the tax bill would be $\$ 148,750$. The present value at $6 \%$ interest rate of these two tax revenue streams between a firm's eleventh and seventeenth year are $\$ 355,338$ and $\$ 463,654$, respectively. Remembering that the extra seven years tax exemption correlated with 312 and 518 promoted jobs, each new job cost the government the equivalent of between $\$ 647$ and $\$ 1,486$ in $\operatorname{tax}$ revenue. 
Based on these direct cost calculations and after adjusting for exaggeration by a factor of three, PRIDCO construction is clearly far less expensive, or more profitable, than extra years of tax exemption, Table 5 .

TABLE 5

Direct Government Cost Per Promoted Job (discounted present values)

PRIDCO Construction

San Juan Zone

Most Rural Zone

Seven Extra Years

Tax Exemption

$$
-\$ 105
$$$$
\$ 174
$$

$\$ 1,941$ to

to

to
$-\$ 1,599$

$\$ 2,133$

$\$ 4,458$

2. Additional Considerations. While the net after-tax government costs presented above were reasonably straightforward, more complete calculations are considerably more difficult. Additional variables influencing costs include the plant occupancy rates, the life and profitability of tax exempt corporations, the previous employment of promoted employees, the number of firms that would have located in the incentives' absence, the personal income taxes paid by the new employees, and the incentives' administrative costs.

First, the direct cost calculations assumed that each plant would be uniformly, but not fully, occupied throughout 16 years. Nevertheless, vacancy's effect on the building's net cost is greater when the building is newer than when it is older. For example, for a 16 year building at $6 \%$ interest, two years vacancy immediately after construction and during the last two years of the building's life reduces the present value of the rents by $18 \%$ and $8 \%$, respectively.

Second, the tax exemption cost calculations are based on two assumptions: 
1) that firms continue operating through their seventeenth year; and 2) that firms earn average profits from their tenth to seventeenth years. But a substantial number of firms are likely to discontinue operations before their eleventh year and the surviving firms are likely to be more profitable than average. A firm attracted by the extra seven years exemption which closes before its eligibility costs the government nothing. On the other hand, the surviving, more profitable firms are most costly since their exempted income taxes are greater. Although data required to evaluate the net effects on cost--data on firms' years in operation and profits of older firms--do not exist, the exemption job's cost is unlikely to be substantially biased by these offsetting influences.

Third and fourth, the previous earnings of employees who took jobs in newly promoted firms and the proportion of firms that would have located in the incentives absence are important determinants of incentive costeffectiveness. Two extremes are possible. If all employees of the new firms had previous jobs with similar wages in firms that did not hire previously unemployed replacements, or if the firm would have located in the absence of the incentives, then the incentives only represent a government transfer to the promoted firms. At the other extreme, if all new employees were unemployed and if the firms would not have located in the absence of the incentives, the new jobs may properly be attributed to the incentives.

Since all promoted jobs are not likely to be new to the economy and since no information on the previous employment of promoted firm employees is available, the estimated cost per new job has a downward bias that cannot be corrected. On the other hand, since the model was structured to account for the influence on firms of non-incentive locational factors such as municipal size and transport facilities, no modification of the cost-effectiveness should 
be required even if direct information on the proportion of firms that would have located in the incentives absence were available.

Fifth, incremental personal income taxes are likely to offset part of the direct cost of the incentives. For example, assume that each worker earns the average yearly manufacturing wage and salary income, $\$ 3,000$, and pays a $20 \%$ tax on $\$ 369$ according to the 1970 tax schedule and assuming two dependents. The yearly tax bill paid by each employee of a firm attracted by the incentives is therefore $\$ 74$. At a six percent interest rate, the present value of $\$ 74$ over 17 years is $\$ 775$. Interestingly, if the new firm and job last forever, the present value of the personal income taxes is $\$ 1,233$ which does not pay the calculated tax exemption job cost.

Finally, the cost per new job must include expenses required for administration of the incentives programs. The annual budgets of the sections in PRIDCO charged with construction supervision and rent collection and of the section in EDA charged with promotions must be included in the costs of jobs attributable to PRIDCO construction. Similarly, the sections in EDA and the Department of Revenue which rule on eligibility and supervise allowed exemptions must also figure as a cost of the jobs attributable to tax exemptions. While no information for evaluating these costs is available, the author suspects that the average (or margina1) cost per job attributable to PRIDCO construction is higher than the cost per job attributable to the tax exemptions.

3. Conclusion. While the direct costs of jobs attributable to PRIDCO construction are substantially less than the costs of jobs attributable to the extra years of tax exemption, it is impossible to evaluate the actual net costs, or even cost rankings, of the two incentive programs. When consideration is made for the promotional exaggeration and the increased personal 
income taxes, the cost per job attributable to PRIDCO construction and to the extra tax exemption in rural municipalities becomes $\$ 1,599$ revenue to $\$ 2,133$ cost and $\$ 1,941$ to $\$ 4,458$, respectively. Nevertheless, plant vacancies increased PRIDCO job costs, and previously employed promoted employees and administration costs raise both PRIDCO and tax exemption job costs. In the absence of necessary data, an evaluation of actual incentive job costs, or even of their ranking, is impossible. 


\section{Footnotes}

* This research was supported in part by a grant from the Puerto Rico Economic Development Administration. The author wishes to thank Charles Leven, David Felix, Juan Lopez Mangual, Mark Frankena, James MacMillan, and James Seldon for their helpful comments. Remaining errors are the responsibility of the author.

** The author is an assistant professor of Economics at the University of Western Ontario.

1 Transportation costs differences among municipalities are small relative to total shipping costs. Additionally, changes in transportation costs are found to be insignificant in the empirical analysis, p. 25.

${ }^{2}[6,206$ and 7,204$]$.

${ }^{3}[18,107]$.

${ }^{4}[18]$

$5[15]$.

$6[10,20]$

7 This section, like the minimum wage section, draws heavily from L. Reynolds and P. Gregory [15, Ch. 2].

${ }^{8}[15,43]$

${ }^{9}$ Although Puerto Rico is a Commonwealth associate of the United States, corporate and private residents of the island pay no taxes to the United States Treasury. While corporations from outside the United states are eligible for the Puerto Rican incentives such as the tax exemption, their Puerto Rican profits may (or may not) be taxed by their home country. 
${ }^{10} \mathrm{P}<.10$ indicates that the significance level is less than .10 . ${ }^{11}$ Annual PRIDCO Reports. 


\section{BIBLIOGRAPHY}

1. Baer, Werner. The Puerto Rico Economy and United States Economic Fluctuations. San Juan: University of Puerto Rico, 1962.

2. Barton, Hugh C. "Puerto Rico's Industrial Development Program: 1942-60." Paper presented at a Seminar of the Center for International Affairs, Harvard University, 1959.

3. - "Economic Development in Puerto Rico During the Last Seventeen Years." San Juan: Economic Development Administration, n.d. (approximately 1967).

4. Bhatia, Mohinder S. "Tax Exemption in a Developing Economy: A Case Study of Puerto Rico," National Tax Journal, XIII (December 1960), 341-349.

5. Bird, Richard M. "Tax-Subsidy Policies for Regional Development," National Tax Journal XIX (June 1966), 113-124.

6. Borts, George J. "Criteria for the Evaluation of Regional Development Programs" in Regional Accounts for Policy Decisions, Werner Hirsch, ed., Baltimore: Johns Hopkins, 1966, 183-218.

7. Borts, G. H. and Stern, J. L. Economic Growth in a Free Market, New York: Columbia University Press, 1964, 204.

8. Bridges, Benjamin. "State and Local Inducements for Industry," National Tax Journal, XVIII (March 1965), 1-15; and XVIII (June 1965), 175-192.

9. Kauffman, Kenneth M. "Income Tax Exemption and Economic Development," Nationa1 Tax Journa1, XIII (June 1960), 141-162; and XIII (September 1960), 252-269.

10. Negociado de Planos Reguladores. "Estudio para Determinar la Agrupacion Funcional de los Municipios de Puerto Rico para Propositos de Planificacion," Junta de Planificacion, San Juan, Puerto Rico, 1962. 
11. Puerto Rico Industrial Development Corporation. "Yearly Reports of Promoted Factories: 1960-61, ... 1969-70," San Juan: Puerto Rico Industrial Development Corporation (mimeographed).

12. Puerto Rico Planning Board. "Indicadores Socio-Economicos por Regiones (Anos Seleccionados)." San Juan: Puerto Rico Planning Board, 1970. 13. - Statistical Yearbook: 1967. San Juan: Graficart Co., n.d.

14. Ramos, Frank. "Fancy Figuring is a Fomento Fact," The San Juan Star, August 16, 1971.

15. Reynolds, Lloyd G., and Peter Gregory. Wages, Productivity, and Industrialization in Puerto Rico. Homewood, Illinois: Richard Irwin Inc., 1965.

16. Stober, William J., and Laurence H. Falk. "The Effect of Financial Inducements on the Location of Firms," Southern Economic Journal, XXXVI (July 1969), 25-35.

17. Suits, Daniel B. "Use of Dummy Variables in Regression Equations," American Statistical Association Journal, LII (December 1957), 548-551.

18. Thurow, Lester C. "Puerto Rican Industrialization Incentives for the 1970 's and 1980's." Report prepared for the Puerto Rican Planning Board (December 1970).

19. U.S. Bureau of the Census. Census of Manufactures: 1967, PUERTO RICO. (MC67-PR). Washington: U.S. Government Printing Office, 1970.

20. Woodward, Robert S. "Industrial Incentives and Regional Economic Growth: The Case of Puerto Rico," unpublished Ph.D dissertation, Washington University, 1972. 